\title{
Selective absorption of water from different oil-water emulsions with Psy-cl-poly(AAm) synthesized using irradiation copolymerization method
}

\author{
B S KAITH* and KIRAN KUMAR \\ Applied Chemistry Research Laboratory, National Institute of Technology (Deemed University), \\ Hamirpur 177 005, India
}

MS received 12 March 2007; revised 28 May 2007

\begin{abstract}
The present paper deals with the functionalization of psyllium with acrylamide under the influence of gamma radiation using hexamethylene tetramine as a crosslinker. The polymer synthesized was characterized using FTIR spectroscopy, scanning electron microscopy and thermogravimetric analysis. The superabsorbent was then used further for the selective absorption of water from different oil-water emulsions.
\end{abstract}

Keywords. Oil-water emulsions; hydrogel; water absorption; psyllium; acrylamide.

\section{Introduction}

Bio-polymers being cost-effective, biodegradable and quite effective in nature are variously modified by scientists for use in technological processes such as water treatment processes (Agarwal et al 2002; Mishra et al 2004), drug delivery technologies (El-Sherbiny et al 2005; Nakamura et al 2006) and membrane technologies (Iwata and Matsuda 1988). The use of these modified products is finding widened applications in various industries. Controlled drug delivery devices (Zou et al 2005), removal of hazardous metal ions (Rifi et al 1995; Ciesielski and Tomasik 2003) from industrial effluents and great potential as flocculent (Yan et al 2004; Pal et al 2006) are some of the highlighted uses. Removal of water from petroleum products during the refining process in oil industries is one of the major problems. In this paper, work on synthesis of hydrogels from psyllium and acrylamide using hexamethylene tetramine as a crosslinker under the influence of gamma radiation and its application in selective removal of water from different water-oil emulsions is reported.

\section{Experimental}

\subsection{Materials and method}

Psyllium (Sidhpur Sat-Isabgol Factory), acrylamide (LOBA Chemie Pvt. Ltd.) and hexamethylene tetramine (LOBA Chemie Pvt. Ltd.) were used as received.

*Author for correspondence

(bskaith@yahoo.co.in; kaith@nitham.ac.in)
Weighing was done on electronic balance (Libror AEG220, Shimadzu), FTIR spectra were recorded in $\mathrm{KBr}$ pellets using Perkin Elmer spectrophotometer, SEM of the samples were taken on Jeol Steroscan 150 Microscope and thermogravimetric analysis was done on Leinsis thermal analyser. Source of gamma-radiation used was Co-60 and the dose rate used was $2.592 \mathrm{KGy} / \mathrm{h}$.

\subsection{Synthesis of Psy-cl-poly(AAm)}

Psyllium was graft copolymerized with acrylamide using hexamethylene tetramine as a crosslinker under the influence of gamma radiation. Reaction parameters such as radiation dose and amount of solvent were optimized in the beginning, so as to get maximum graft yield. Percent grafting $\left(P_{\mathrm{g}}\right)$ was calculated using the following equation

$$
P_{\mathrm{g}}=\frac{W_{\mathrm{f}}-W_{\mathrm{b}}}{W_{\mathrm{b}}} \times 100,
$$

where $W_{\mathrm{f}}$ is the weight of functionalized polymer, $W_{\mathrm{b}}$ the weight of backbone polymer.

Monomer and crosslinker concentrations were optimized so as to get maximum percent swelling. The optimized product was used for further investigations.

\subsection{Water absorption from different oil-water emulsions}

$100 \mathrm{mg}$ of the polymer was immersed separately in different oil-water $(1: 1)$ emulsions with constant shaking on automatic shaking machine and was studied for its efficiency in selective absorption of water as a function of time $(4,8,12,16$ and $24 \mathrm{~h})$, temperature $(25,30,35$, 
40 and $\left.45^{\circ} \mathrm{C}\right), \mathrm{pH}$ and $\mathrm{NaCl}$ concentration $(1,5,10$ and $15 \%)$. Percent swelling was calculated using the equation

$$
P_{\mathrm{s}}=\frac{\left(W_{\mathrm{s}}-W_{\mathrm{d}}\right)}{W_{\mathrm{d}}} \times 100,
$$

where $W_{\mathrm{s}}$ and $W_{\mathrm{d}}$ are the weights of swollen polymer and dry polymer, respectively.

\section{Results and discussion}

$-\mathrm{OH}$ groups of arabinoxylan present in the mucilaginous part of psyllium act as active sites for the graft copolymerization of acrylamide onto it. The mechanism for the same can be presented as:

Initiation:

$$
\begin{aligned}
& \mathrm{nM} \stackrel{\text { Radiations }}{\longrightarrow} * \mathrm{M}_{n}, \\
& \mathrm{H}_{2} \mathrm{O} \stackrel{\text { Radiations }}{\longrightarrow} \mathrm{H}^{*}+* \mathrm{OH}, \\
& \mathrm{Psy}-\mathrm{OH} \stackrel{\text { Radiations }}{\longrightarrow} \text { Psy-O } *+\mathrm{H}^{*}, \\
& \mathrm{Psy}-\mathrm{OH}+* \mathrm{OH} \rightarrow \text { Psy-O } *+\mathrm{H}_{2} \mathrm{O}, \\
& \mathrm{M}+* \mathrm{OH} \rightarrow * \mathrm{M}-\mathrm{OH} .
\end{aligned}
$$

Propagation:

$$
\begin{aligned}
& \text { Psy-OH + *M-OH } \rightarrow \text { Psy-O-M*+ } \mathrm{H}_{2} \mathrm{O}, \\
& \text { Psy-O-M* + nM } \rightarrow \text { Psy-O-(M) }{ }_{n}-\mathrm{M}^{*}, \\
& \text { Psy-O }+\mathrm{nM} \rightarrow \text { Psy-O-(M) }{ }_{n-1} \mathrm{M}^{*}, \\
& * \mathrm{M}-\mathrm{OH}+\mathrm{nM} \rightarrow \text { HO-(M) })_{n}-\mathrm{M}^{*} .
\end{aligned}
$$

Termination:

$$
\begin{aligned}
& \text { Psy-O-(M) })_{n}-\mathrm{M}^{*}+\mathrm{M}^{*}-(\mathrm{M})_{n}-\mathrm{O}-\mathrm{Psy} \rightarrow \\
& \text { Psy-O-(M) }{ }_{n}-\mathrm{M}_{2}-(\mathrm{M})_{n}-\mathrm{O}-\mathrm{Psy} \text {, } \\
& \text { Graft co-polymer } \\
& \text { Psy-O-(M) })_{n-1} \mathrm{M}^{*}+\mathrm{M}^{*}-(\mathrm{M})_{n-1}-\mathrm{O}-\mathrm{Psy} \rightarrow \\
& \text { Psy-O-(M) }{ }_{n-1}-\mathrm{M}_{2}-(\mathrm{M})_{n-1}-\mathrm{O}-\mathrm{Psy} \\
& \text { Graft co-polymer } \\
& \text { Psy-O-(M) } \left.)_{n}-\mathrm{M}^{*}+* \mathrm{OH} \rightarrow \text { Psy-O-(M) }\right)_{n+1}-\mathrm{OH} \text {, } \\
& \mathrm{HO}-(\mathrm{M})_{n}-\mathrm{M}^{*}+* \mathrm{M}-(\mathrm{M})_{n}-\mathrm{OH} \rightarrow \\
& \mathrm{HO}-(\mathrm{M})_{n}-\mathrm{M}_{2}-(\mathrm{M})_{n}-\mathrm{OH} \text {. } \\
& \text { Homopolymer }
\end{aligned}
$$

$\mathrm{M}^{*}=$ monomer free radical; $\mathrm{Psy}-\mathrm{O}^{*}=$ backbone free radical.

Multifunctional nature of hexamethylene tetramine leads to the formation of networks between psyllium and poly(AAm) leading to the formation of three dimensional network (Kaith and Kumar 2007).

\subsection{Optimization of reaction parameters}

Figure la shows the effect of radiation time onto percent grafting. It was observed that with increase in radiation time, $P_{\mathrm{g}}$ first increases up to $10 \mathrm{~h}$ and then decreases. It is due to the fact that with increase in radiation time the active sites on both the backbone and monomer increases leading to increase in grafting but once optimum is reached the concentration of the free radicals limit the length of the polymeric chain by initiating numerous chains simultaneously, hence resulting in decreased $P_{\mathrm{g}}$.

It is quite evident from figure $1 \mathrm{~b}$ that $P_{\mathrm{g}}$ increases with increase in amount of solvent up to $20 \mathrm{ml}$ and then decreases with further increase in amount of solvent. This can be explained on the basis that with increase in amount of solvent at first the concentration of $* \mathrm{OH}$ is appropriate for the propagation of polymerization, but the observed decrease in $P_{\mathrm{g}}$ with its further increase is due to termination of polymerization (Kaith and Kumar 2007).

Figure 1c shows that with increase in monomer concentration the percent swelling first increases $(825 \%)$ up to $7.03 \times 10^{-1} \mathrm{~mol} \mathrm{~L}^{-1}$ and then it decreases. This is due to predominance of homo-polymerization over graft copolymerization.

Similar trend has been observed with variation in crosslinker concentration. Here also, there is initial increase in percent swelling $(1667 \%)$ with increase in crosslinker concentration up to $5.349 \times 10^{-2} \mathrm{~mol} \mathrm{~L}^{-1}$ followed by decrease in $P_{\mathrm{s}}$ with further increase in crosslinker concentration. This is due to increasing crosslinking density with increase in crosslinker concentration resulting in smaller pore size and lesser approachability of solvent towards the matrix.

\subsection{Characterization}

3.2a FTIR spectroscopy: Psyllium showed peaks at $3780.9 \mathrm{~cm}^{-1}$ and $3427.6 \mathrm{~cm}^{-1}(\mathrm{O}-\mathrm{H}$ stretching bonded absorption of carbohydrates), $2925.8 \mathrm{~cm}^{-1}\left(\mathrm{CH}_{2}\right.$ asymmetric stretching), $1378.8 \mathrm{~cm}^{-1}\left(\mathrm{CH}, \mathrm{CH}_{2}\right.$ and $\mathrm{OH}$ inplane bending in carbohydrates), $1039.5 \mathrm{~cm}^{-1}(\mathrm{C}-\mathrm{O}$ stretching region as complex bands, resulting from $\mathrm{C}-\mathrm{O}$ and $\mathrm{C}-\mathrm{O}-\mathrm{C}$ stretching vibrations), $897 \mathrm{~cm}^{-1}$ and $533 \mathrm{~cm}^{-1}$ (pyranose rings).

Psy-cl-poly(AAm), on the other hand, showed peaks at $1662.9 \mathrm{~cm}^{-1}$ (C=O stretching of amide-I band), $1323.5 \mathrm{~cm}^{-1}$ ( $\mathrm{N}-\mathrm{H}$ in-plane bending of amide-II band), $1250.4 \mathrm{~cm}^{-1}$ (C-N stretching and $\mathrm{N}-\mathrm{H}$ in-plane bending of amide-III band), $896.9 \mathrm{~cm}^{-1}$ ( $\mathrm{CH}_{2}$ in-plane bending), $615.8 \mathrm{~cm}^{-1}$ (OCN deformations of amide-IV band), apart from peaks obtained with psyllium.

3.2b Scanning electron microscopy: SEM studies were conducted to demarcate the morphological differences on the surface of both psyllium and Psy-cl-poly(AAm). Figu- 

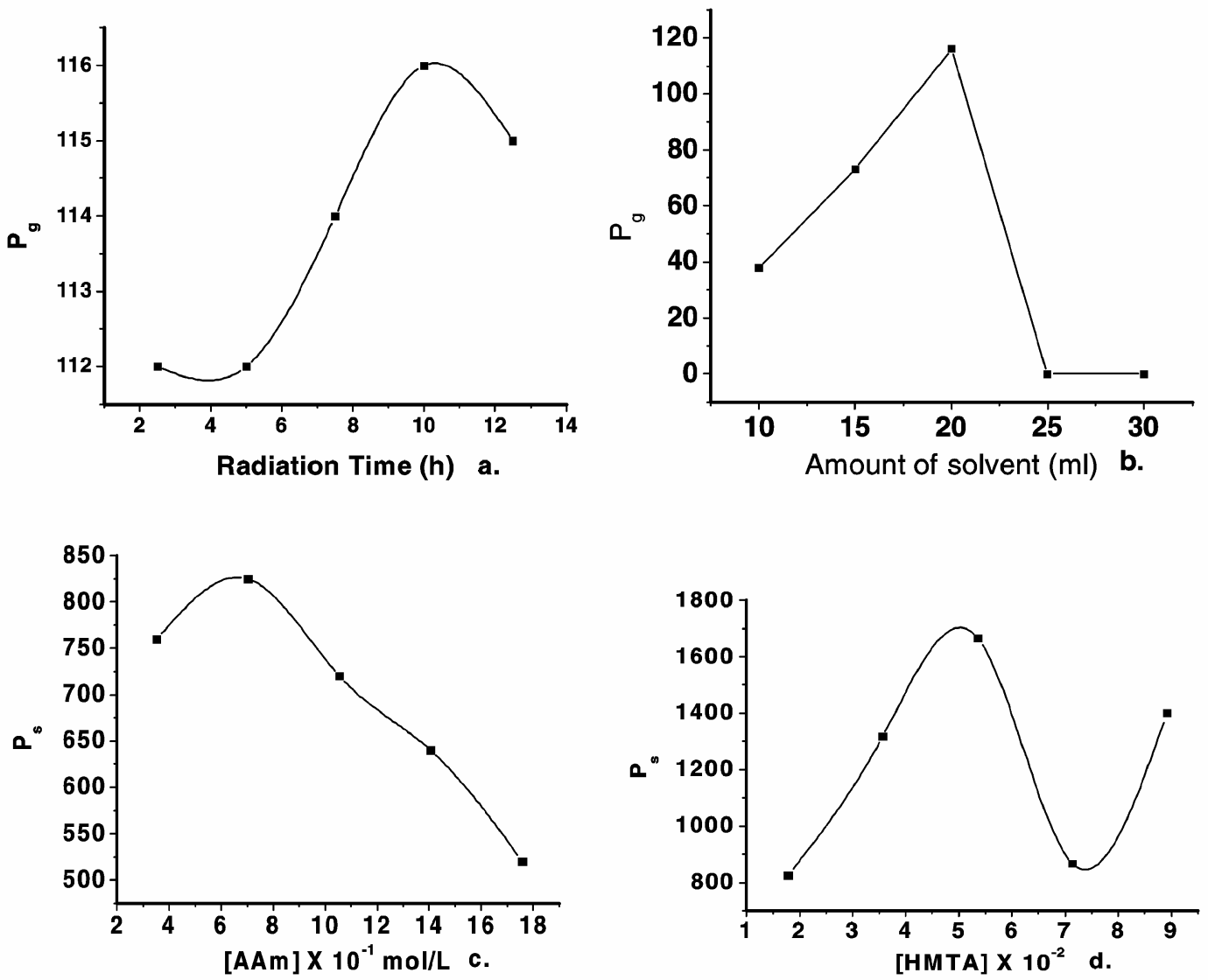

Figure 1. a. Effect of radiation time onto percent grafting. (Radiation dose $=2.592 \mathrm{KGy} / \mathrm{h}$ ), b. effect of amount of solvent onto percent grafting. ([AAm $]=7.03 \times 10^{-1} \mathrm{~mol} \mathrm{~L}^{-1}$, psy $=1 \mathrm{~g}$, reaction time $=10 \mathrm{~h}$ ), c. effect of monomer concentration onto percent swelling $\left(\left[\right.\right.$ HMTA] $=1.783 \times 10^{-2} \mathrm{~mol} \mathrm{~L}^{-1}$, reaction time $=10 \mathrm{~h}$ ) and $\mathbf{d}$. effect of crosslinker concentration onto percent swelling. $\left([\mathrm{AAm}]=7.03 \times 10^{-1} \mathrm{~mol} \mathrm{~L}^{-1}\right.$, reaction time $\left.=10 \mathrm{~h}\right)$.
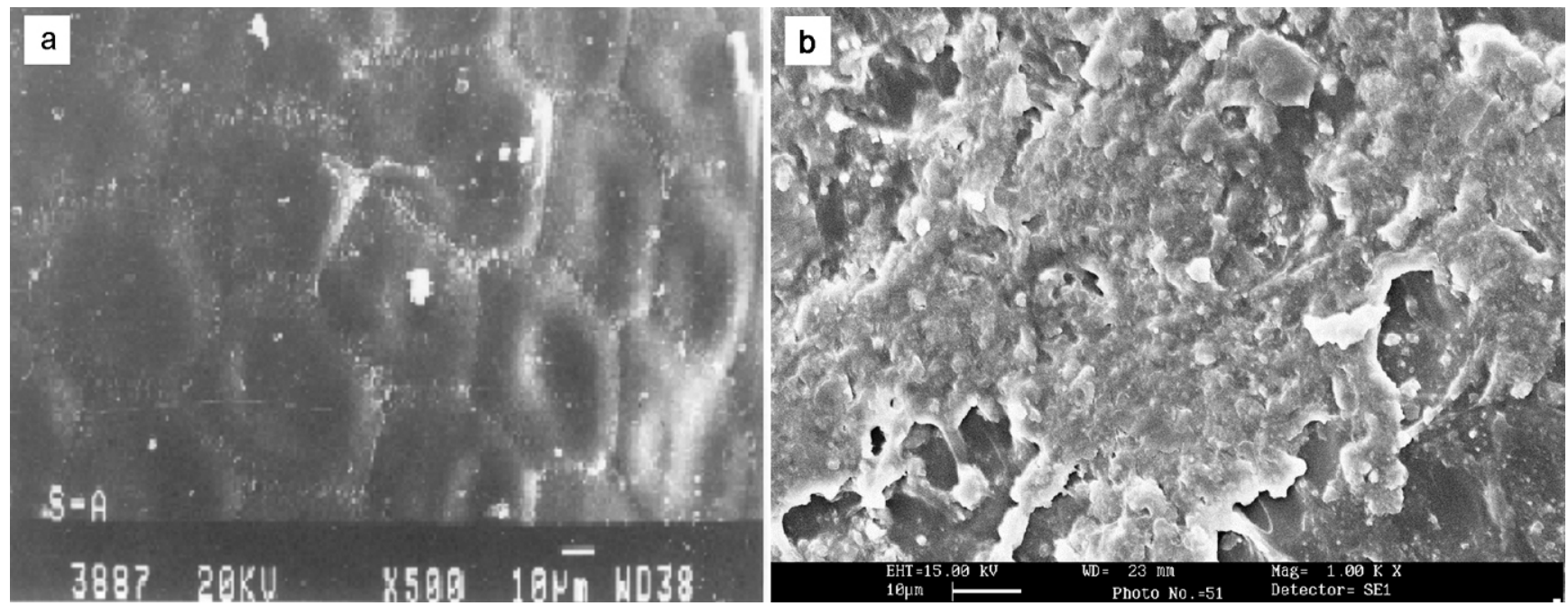

Figure 2. a. SEM of psyllium and b. SEM of Psy-cl-poly(AAm). 


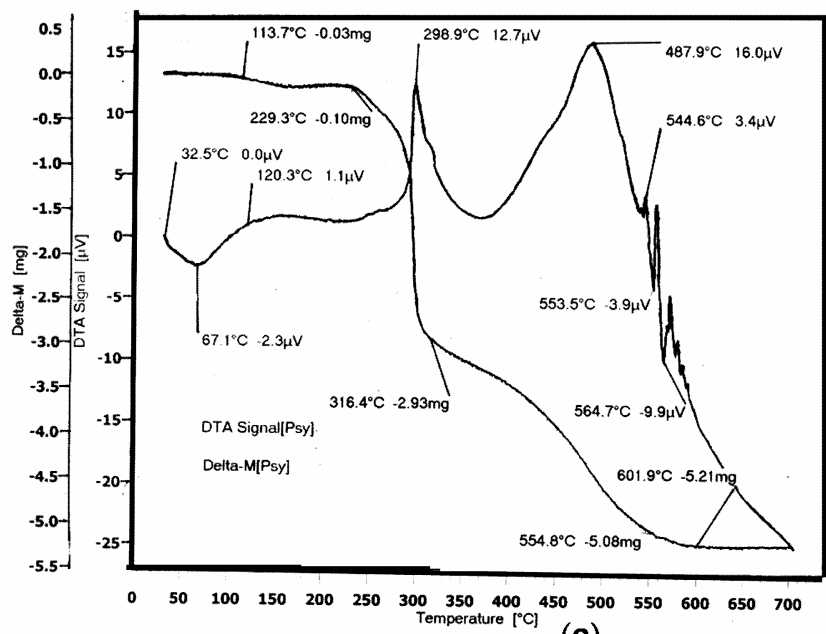

(a)

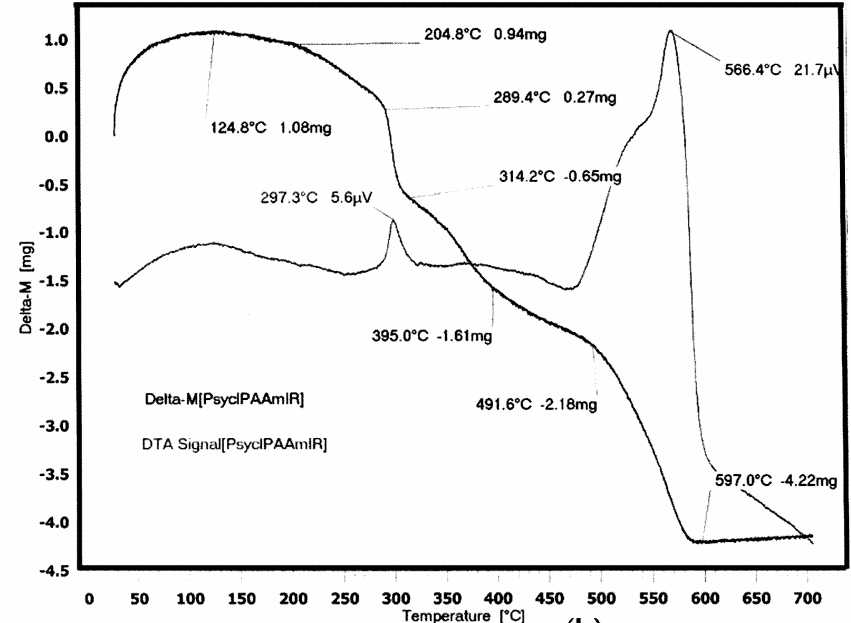

(b)

Figure 3. (a) TGA/DTA of psyllium and (b) TGA/DTA of Psy-cl-poly(AAm)
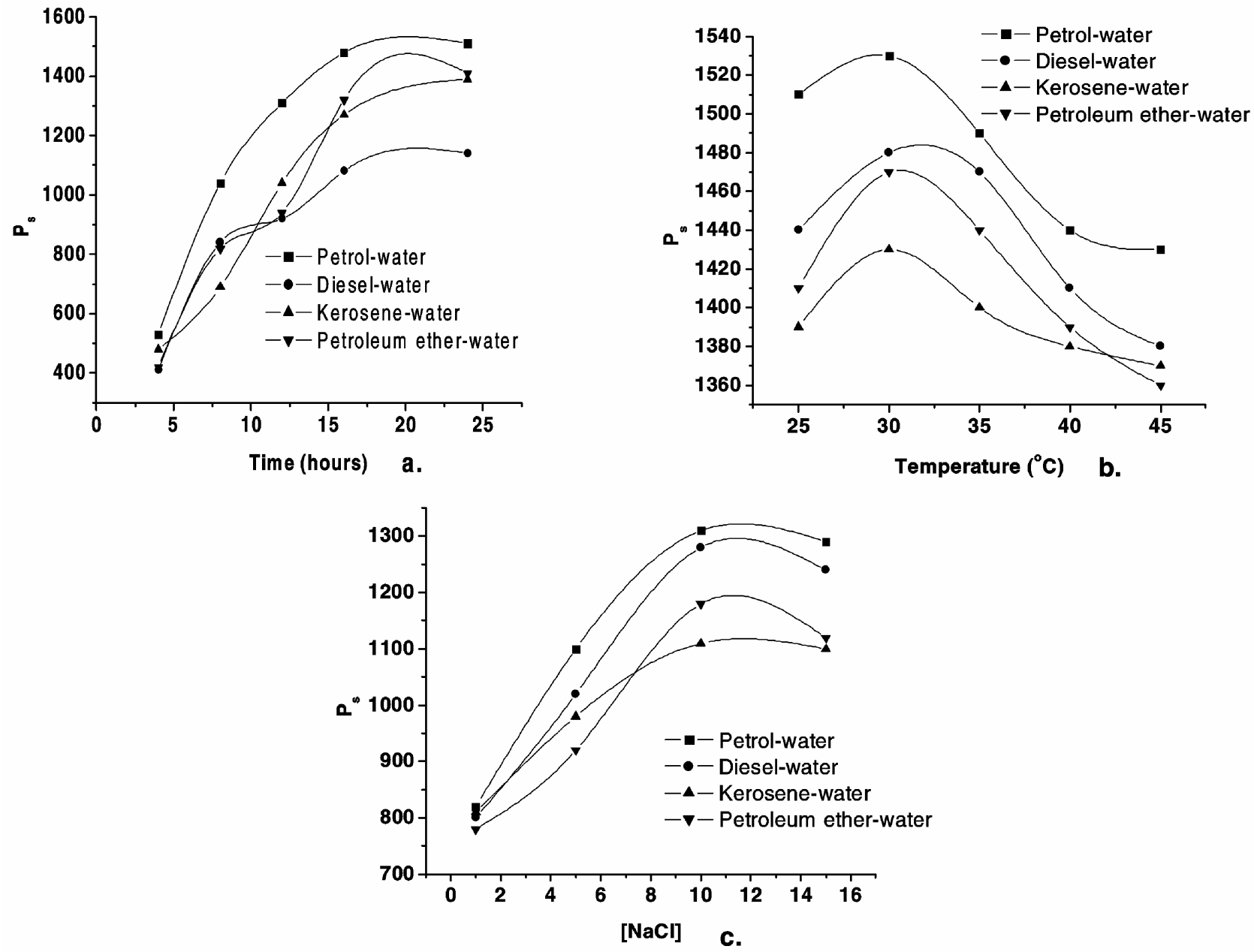

Figure 4. a. Effect of time onto percent swelling $\left(P_{\mathrm{s}}\right)$ of Psy-cl-poly $(\mathrm{AAm})$ in different oil-water emulsions, $\mathbf{b}$. effect of temperature on to percent swelling $\left(P_{\mathrm{s}}\right)$ of Psy-cl-poly $(\mathrm{AAm})$ in different oil-water emulsions and $\mathbf{c}$. effect of $\mathrm{NaCl}$ concentration on to percent swelling $\left(P_{\mathrm{s}}\right)$ of Psy-cl-poly $(\mathrm{AAm})$ in different oil-water emulsions. 
res $2 \mathrm{a}$ and $\mathrm{b}$ clearly show the marked difference between psyllium having smooth homogeneous surface and Psycl-poly(AAm) with heterogeneous network structure.

3.2c Thermogravimetric analysis: TGA/DTA studies of both the backbone and functionalized polymer were performed as function of percent weight loss vs temperature (figures $3 \mathrm{a}$ and $\mathrm{b}$ ). Psyllium shows initial decomposition temperature at $229.3^{\circ} \mathrm{C}$ and final decomposition temperature at $601.9^{\circ} \mathrm{C}$, while Psy-cl-poly(AAm) synthesized under the influence of radiations showed initial decomposition temperature of $204 \cdot 8^{\circ} \mathrm{C}$ and final decomposition temperature of $597 \cdot 0^{\circ} \mathrm{C}$. Two-stage decomposition in both the cases was observed. Psyllium showed one endothermic peak at $67 \cdot 1^{\circ} \mathrm{C}(-2 \cdot 3 \mu \mathrm{V})$ and two exothermic peaks at $298.9^{\circ} \mathrm{C}(12.7 \mu \mathrm{V})$ and $487.9^{\circ} \mathrm{C}(16.0 \mu \mathrm{V})$. On the other hand, Psy-cl-poly(AAm) showed two exothermic peaks at $297 \cdot 3^{\circ} \mathrm{C}(5 \cdot 6 \mu \mathrm{V})$ and $566.4^{\circ} \mathrm{C}(21.7 \mu \mathrm{V})$.

\subsection{Water absorption studies from different oil-water emulsions}

3.3a Effect of time onto $P_{s}$ : Water absorption was investigated at different intervals of time $(4,8,12,16,24 \mathrm{~h})$. It was observed that absorption increases with increase in time attaining equilibrium swelling after $24 \mathrm{~h}$. This is due to the saturation of pores present in the polymeric matrix with solvent molecules (figure $4 a$ ).

$3.3 \mathrm{~b}$ Effect of temperature onto $P_{s}$ : Temperature of the absorption media was varied from $25-45^{\circ} \mathrm{C}$. It was observed that with increase in temperature there was a slight increase in absorption up to $35^{\circ} \mathrm{C}$ after which it decreased continuously (figure $4 \mathrm{~b}$ ). It can be explained on the basis that within this temperature the adsorbent got compacted resulting in desorption of the solvent (Kaith and Kumar 2007).

3.3c Effect of $p H$ onto $P_{s}$ : Water absorption from different oil-water emulsions was investigated as a function of $\mathrm{pH}$ $(0.5 \mathrm{~N} \mathrm{NaOH}$, distilled water, $0.5 \mathrm{~N} \mathrm{HCl})$. It was observed that the polymer got disintegrated in both the alkaline and acidic medium. This is due to the reason that the polymeric matrix is unstable in acidic as well as basic medium, hence it got disintegrated.

3.3d Effect of $\mathrm{NaCl}$ concentration onto $P_{s}$ : Figure 4c shows the effect of change in $\mathrm{NaCl}$ concentration $(1,5,10$, $15 \%$ ). It was observed that the absorption of water from different oil-water emulsions increases up to $10 \%$ and then it decreases. It can be explained on the basis that in $\mathrm{Na}^{+} \mathrm{Cl}^{-}$solution, $\mathrm{Na}^{+}$enters inside the matrix and being hydrophilic in nature attracts more of the solvent molecules towards the matrix.

\section{Conclusions}

It can be concluded from foregone discussion that the synthesized hydrogel [Psy-cl-poly(AAm)] can selectively absorb water from different oil-water emulsions and is, therefore, of great importance from industrial point of view. Moreover, the gel was found to act as smart polymer being $\mathrm{pH}$ and temperature dependent. The gel can, therefore, be used as controlled drug delivery device and various other technological processes.

\section{References}

Agarwal M, Srinivasan R and Mishra A 2002 J. Polym. Res. 9 69

Ciesielski W and Tomasik P 2003 Thermochimica Acta 403 161

El-Sherbiny I M, Lins R J, Abdel-Bary E M and Harding D R K 2005 Eur. Polym. J. 412584

Iwata H and Matsuda T 1988 J. Membrane Sci. 38185

Kaith B S and Kumar K 2007 e-Polymers (submitted)

Mishra A, Srinivasan R, Bajpai M and Dubey R 2004 Colloid Polym. Sci. 282722

Nakamura K, Nara E and Akiyama Y 2006 J. Controlled Release 111309

Pal S, Mal D and Singh R P 2006 Colloids and Surfaces A: Physicochem. Eng. Aspects 289193

Rifi E H, Rastegar F and Brunette J P 1995 Talanta 42811

Yan Y D, Glover S M, Jameson G J and Biggs S 2004 Int. J. Miner. Process 73161

Zou M, Okamoto H, Cheng G, Hao X, Sun J, Cui F and Danjo K 2005 Eur. J. Pharmaceutics and Biopharmaceutics 59 155 